\title{
Hand-Assisted Laparoscopic Hepatectomy for Primary Clear Cell Hepatocellular Carcinoma of the Liver
}

\author{
Kazutoshi Kida Takatsugu Oida Kenji Mimatsu \\ Hisao Kano Atsushi Kawasaki Nobutada Fukino \\ Youichi Kuboi \\ Department of Surgery, Social Insurance Yokohama Central Hospital, \\ Yokohama, Japan
}

\section{Key Words}

Hand-assisted laparoscopic hepatectomy · Primary clear cell hepatocellular carcinoma $\cdot$ Hepatocellular carcinoma

\begin{abstract}
We report a case of primary clear cell hepatocellular carcinoma of the liver (PCCCL) for which we performed hand-assisted laparoscopic hepatectomy. A 71-year-old female with hepatitis $\mathrm{C}$ infection and diabetes mellitus was admitted to our department for a hepatic tumor with gallstone. Abdominal computed tomography revealed a tumor $25 \mathrm{~mm}$ in diameter on the surface in segment 5 of the liver. The imaging results suggested small hepatocellular carcinoma located on the surface in segment 5 of the liver, and we performed laparoscopic surgery aiming at a minimally invasive procedure. We performed laparoscopic cholecystectomy and hand-assisted laparoscopic hepatectomy. Histopathological findings showed moderately differentiated hepatocellular carcinoma, and as the proportion of clear cells was $75 \%$, the tumor was diagnosed as PCCCL. This is the first report of hand-assisted laparoscopic hepatectomy for PCCCL. Laparoscopic hepatectomy is a useful minimally invasive surgical procedure when the tumor is located on the surface of the liver.
\end{abstract}

\section{Introduction}

Hepatocellular carcinoma (HCC) often develops against a background of chronic viral hepatitis. However, primary clear cell hepatocellular carcinoma of the liver (PCCCL) is a specific and rare subtype of primary HCC. Clear cell HCC is not frequent and has been reported to account for $2.2-6.7 \%$ of all resectable HCCs $[1,2]$. The 
existence of clear cells as well as fatty change is characteristic of well-differentiated early-stage HCC. Here we report a case of PCCCL who underwent hand-assisted laparoscopic hepatectomy.

\section{Case Report}

A 71-year-old female was admitted to our department for a hepatic tumor with gallstone. She had a history of hepatitis $\mathrm{C}$ infection and diabetes mellitus. Tumor markers such as PIVKA-II (protein induced by vitamin $\mathrm{K}$ absence or antagonist II; normal range $<40 \mathrm{mAU} / \mathrm{ml}$ ) was $101 \mathrm{mAU} / \mathrm{ml}$, and AFP (alpha-fetoprotein; normal range $<10 \mathrm{ng} / \mathrm{ml}$ ) was $5 \mathrm{ng} / \mathrm{ml}$. Abdominal ultrasonography and computed tomography showed a tumor $25 \mathrm{~mm}$ in diameter on the surface in segment 5 of the liver (ig. 1). The lesion was visible on early-phase imaging (fig. 2a) and the tumor was stained on late-phase imaging (fig. 2b) on angiography. In abdominal magnetic resonance imaging the T1-weighted image revealed a well-defined low-intensity area in segment 5, with a high-intensity part inside. The tumor was depicted as a high-intensity area in the T2-weighted image. Angiography showed increased tumor vascularity. The imaging results and laboratory data suggested small HCC located on the surface in segment 5 of the liver, and we performed laparoscopic surgery aiming at a minimally invasive procedure.

A total of three ports were placed. Initially, we performed laparoscopic cholecystectomy. The size of the tumor was measured by laparoscopic ultrasound, and the resection line was marked including a $2 \mathrm{~cm}$ margin around the tumor. Then the size of the intended resection specimen was measured by laparoscopic ultrasound. According to this measurement, a minimal incision was made on the abdominal wall above the tumor for its extraction. The resected specimen was extracted using a plastic bag through the minimal incision. Operative time was $2 \mathrm{~h}$ and no blood transfusion was required.

The postoperative course was uneventful. Histopathological findings showed moderately differentiated HCC, and the proportion of clear cells was 75\%; however, pseudocapsule formation was not revealed in the tumor (fig. 3 ). The tumor was diagnosed as PCCCL.

\section{Discussion}

PCCCL is a specific and rare subtype of primary HCC. Lai et al. [3] suggested that the diagnosis of PCCCL can be made even when the proportion of clear cells is $<30 \%$, while Buchanan and Huvos [4] suggested that PCCCL should be diagnosed when the proportion of clear cells is $>30 \%$. However, most studies diagnosed PCCCL when the proportion of clear cells was $>50 \%$. Using these criteria, PCCCL only accounts for $2.2-6.7 \%$ of all resectable HCCs in most reports $[1,2]$.

The clinicopathological presentations of PCCCL were different from those of common type hepatocellular carcinoma (CHCC). The rates of hepatitis $\mathrm{C}$ infection and capsule formation were higher in PCCCL patients than in those with CHCC; however, no remarkable differences in patients' age, sex, AFP-positive rate or the location, number, size and grade of tumors were observed between the two groups. PCCCL had a better prognosis than CHCC, mainly related to capsule formation, vascular invasion, preoperative liver function and clear cell proportion.

In our case, pseudocapsule formation was not revealed in the tumor. Pseudocapsule formation is an important gross pathologic feature of HCC. Pseudocapsule indicates a relatively positive prognosis after tumor resection. Liu et al. [5] found a higher ratio of pseudocapsule formation in PCCCL than in CHCC microscopically (88.4 vs. 68.0\%; 
$\mathrm{p}<0.05$ ), and pseudocapsule formation might be related to a relatively lower degree of malignancy and a better prognosis for PCCCL. The percentage of pseudocapsule formation was higher in PCCCL than in CHCC $(p<0.05)$ [5].

Surgical resection is an effective treatment for patients with PCCCL and contributes to favorable outcomes and even long-time survival [2]. Many studies have reported PCCCL to have a better prognosis than other HCCs [3, 6]. Liu et al. [1] suggested that 1-, 3- and 5-year survival rates in PCCCL were significantly higher than in CHCC (81, 53 and $39 \%$ vs. 76,46 and $32 \%$; $<<0.021$ ).

Laparoscopic liver resection is now widely used for treating primary and metastatic liver tumors due to its equivalence to open surgery with respect to survival, along with its lower invasiveness. Laparoscopic liver resection is performed via a totally laparoscopic or hand-assisted approach. The total laparoscopic technique has the following drawbacks: (a) possible massive bleeding and air embolism via injured hepatic veins, (b) absence of tactile palpation, and (c) difficulty in extracting intact malignant specimens through the trocar incision. Hand-assisted laparoscopic liver resection was designed to overcome some of these problems. The advantages of hand-assisted laparoscopic liver resection are as follows: (a) it provides better exposure of the anatomy and the possibility of blunt dissection with the assistance of the surgeon's hand, (b) the 'laparoscopic hand' can also provide immediate hemostasis and prevent air embolism even if the branches of the hepatic vein are severed, and (c) if extension of the incision is required for retrieval of intact specimens, it is advantageous for it to have been prepared earlier to facilitate the dissection. The indications for laparoscopic hepatectomy are basically identical to those for open hepatectomy with respect to the preoperative assessment of liver function. Moreover, tumor size and location are important indications for laparoscopic hepatectomy. The indications followed in our department are as follows: (a) tumor factor: tumor size $<4 \mathrm{~cm}$ in diameter for nodular tumors or $<6 \mathrm{~cm}$ in diameter for pedunculated tumors; (b) location: anterolateral segments of the liver (segment 2-6) are the best indications for the laparoscopic approach.

In laparoscopic liver surgery, there are long-standing concerns regarding gas emboli; therefore, laparoscopic surgeons opt for abdominal wall lifting (gasless laparoscopy) or use low $\mathrm{CO}_{2}$ pressures to maintain the pneumoperitoneum in order to minimize risk. In our procedure, before hepatic parenchymal resection, we used low $\mathrm{CO}_{2}$ pressures of $<8 \mathrm{~mm} \mathrm{Hg}$ and after the minimally incision, we used the wall lifting method. As a result, no gas emboli were noted in any patient. The need to convert a laparoscopic procedure to an open procedure commonly occurs due to uncontrollable bleeding. However, in this case, there was no instance of conversion to an open procedure because of lower bleeding due to precoagulation of the liver by using a microwave tissue coagulator along the transection line before and during hepatic parenchymal transection. Moreover, it was easy to control any bleeding with the assistance of the surgeon's hand.

In our case, the proportion of clear cells was 75\%; however, pseudocapsule formation was not found in the tumor. However, the tumor was small without venous invasion, which was thought to give a better prognosis. Fortunately, this tumor was located on the surface in segment 5 of the liver, and we achieved good result by performing laparoscopic hepatectomy. 


\begin{tabular}{r|l|l|l}
$\begin{array}{r}\text { Case Reports in } \\
\text { Gastroenterology }\end{array}$ & $\begin{array}{l}\text { Case Rep Gastroenterol 2012;6:328-332 } \\
\text { DOI: 10.1159/000339460 }\end{array}$ & $\begin{array}{l}\text { Published online: } \\
\text { May 30, 2012 }\end{array}$ & $\begin{array}{l}\text { @ 2012 S. Karger AG, Basel } \\
\text { ISSN 1662-0631 } \\
\text { www.karger.com/crg }\end{array}$ \\
\hline
\end{tabular}

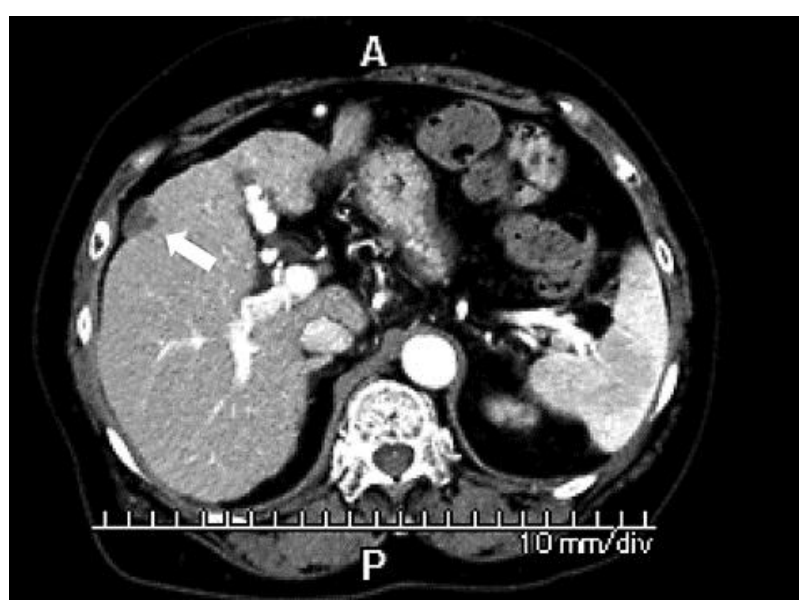

Fig. 1. Abdominal contrast-enhanced computed tomography showed a tumor $25 \mathrm{~mm}$ in diameter on the surface in segment 5 of the liver (arrow).

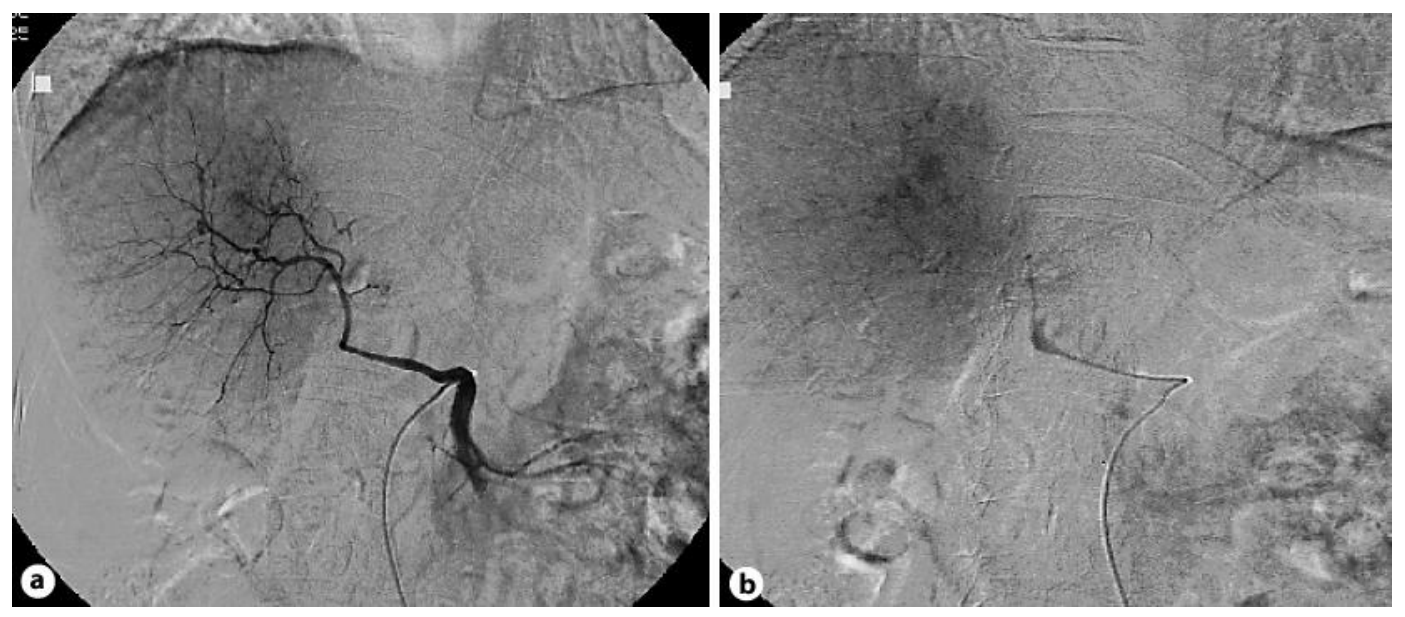

Fig. 2. Angiography showed the lesion on early-phase imaging (a), and tumor was stained on late-phase imaging (b). 


\begin{tabular}{r|l|l|l}
$\begin{array}{r}\text { Case Reports in } \\
\text { Gastroenterology }\end{array}$ & $\begin{array}{l}\text { Case Rep Gastroenterol 2012;6:328-332 } \\
\text { DOI: 10.1159/000339460 }\end{array}$ & $\begin{array}{l}\text { Published online: } \\
\text { May 30, 2012 }\end{array}$ & $\begin{array}{l}\text { @ 2012 S. Karger AG, Basel } \\
\text { ISSN 1662-0631 } \\
\text { www.karger.com/crg }\end{array}$ \\
\hline
\end{tabular}

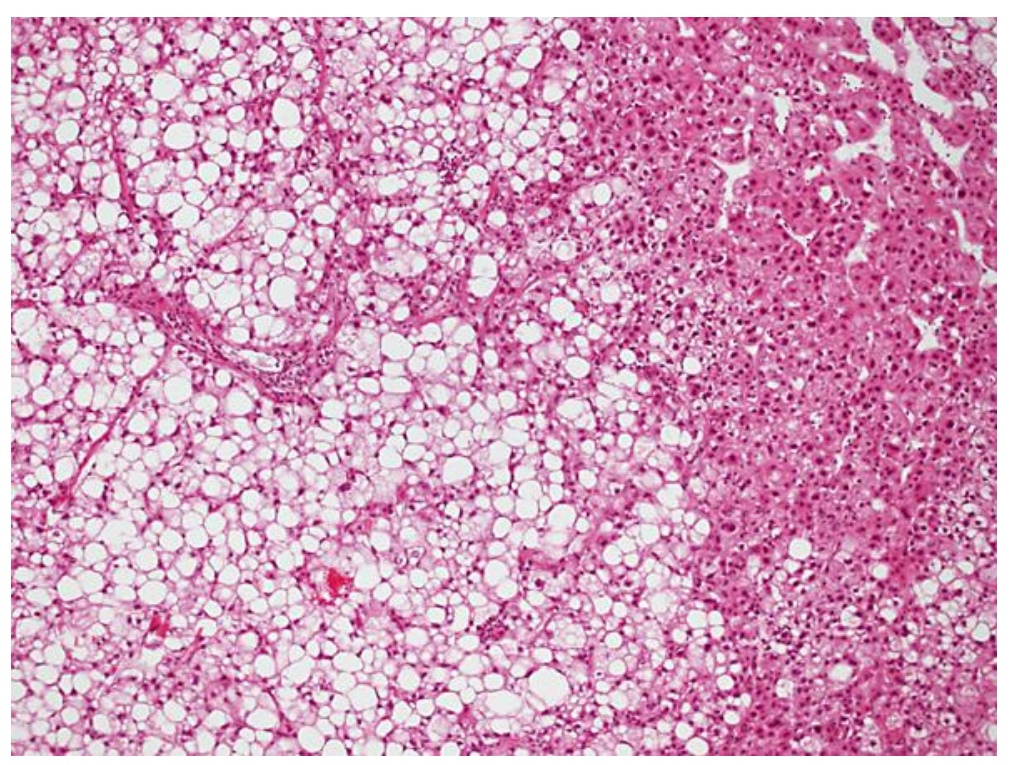

Fig. 3. Histopathological findings showed moderately differentiated HCC, and the proportion of clear cells was 75\%; however, pseudocapsule formation was not shown in the tumor. HE, $\times 100$.

\section{References}

1 Liu Z, Ma W, Lin H, Li Q: Clinicopathological and prognostic features of primary clear cell carcinoma of the liver. Hepatol Res 2008;38:291-299.

-2 Lao XM, Zhang YQ, Jin X, Lin XJ, Guo RP, Li GH, Li JQ: Primary clear cell carcinoma of liver clinicopathologic features and surgical results of 18 cases. Hepatogastroenterology 2006;53:128-132.

-3 Lai CL, Wu PC, Lam KC, Todd D: Histologic prognostic indicators in hepatocellular carcinoma. Cancer 1979;44:1677-1683.

4 Buchanan TF Jr, Huvos AG: Clear-cell carcinoma of the liver. A clinicopathologic study of 13 patients. Am J Clin Pathol 1974;61:529-539.

5 Liu QY, Li HG, Gao M, Lin XF, Li Y, Chen JY: Primary clear cell carcinoma in the liver: CT and MRI findings. World J Gastroenterol 2011;17:946-952.

6 Salvucci M, Lemoine A, Saffroy R, Azoulay D, Lepère B, Gaillard S, Bismuth H, Reynès M, Debuire B: Microsatellite instability in European hepatocellular carcinoma. Oncogene 1999;18:181-187. 